\title{
Myocardial damage due to hypokalaemia and hypophosphataemia
}

\author{
ANDREA FRUSTACI* \\ M.D. \\ FAUSTINO PENNESTRI* \\ M.D. \\ CIRIACO SCOPPETTA $\dagger$ \\ M.D. \\ *Department of Cardiology and $†$ Department of Neurology, Catholic University, Rome, Italy
}

\begin{abstract}
Summary
A case of severe hypokalaemia with stupor, skeletal muscle and heart muscle damage is reported.

An initial infusion of glucose-insulin and potassium (GIK) produced a temporary clinical improvement with reduction of creatine kinase (CKMB) and elevation of serum $\mathrm{K}^{+}$. On the 4th day of treatment, neuromuscular and cardiovascular deterioration occurred accompanied by a further rise of CKMB. This deterioration was coincident with a serum phosphate of $0.26 \mathrm{mmol} / \mathrm{l}$. The impaired left ventricular (LV) function was measured using echocardiography and detecting the ejection fraction (EF).

GIK was stopped and a potassium phosphate infusion commenced. As the phosphate and potassium deficiencies were corrected, the neuromuscular and cardiac abnormalities resolved, CKMB fell to normal and LVEF rose from $40 \%$ to $72 \%$.

We suggest that additional cardiac damage due to hypophosphataemia may have occurred in this patient, who already had cardiac impairment as a result of profound hypokalaemia. Possible mechanisms are discussed.
\end{abstract}

KEY WORDS: diuretic abuse, purgative abuse.

\section{Introduction}

In addition to the well-known electrophysiological effects of hypokalaemia, decreased myocardial contractility with congestive heart failure due to severe potassium depletion has been reported (Potts et al., 1977).

Similarly reversible reduction of myocardial performance (O'Connor, Wheeler and Bethune, 1977) due to hypophosphataemia has been described.

Address for reprints: Dott. Andrea Frustaci, Istituto di Cardiologia, Università Cattolica del S. Cuore, Via della Pineta Sacchetti, 644, 00168 Roma, Italia.
We report a case of heart muscle damage due to combination of hypokalaemia and hypophosphataemia.

\section{Case report}

A 46-year-old woman was admitted with stupor, tetraplegia, congestive heart failure and hypotension. For the last 5 years she had exhibited an extremely severe hypochondriacal neurosis. She had habitually abused laxatives and diuretics. She had had two previous admissions to hospital as a result of electrolyte imbalance. On this admission she was unconscious with motor responses only at the reflex level. She was dehydrated with basal lung rales. The heart rate was regular at 55 beats/min; the heart sounds were muffled with a third sound (S3) present; blood pressure (BP) was $80 / 60 \mathrm{mmHg}$.

Chest X-ray showed cardiomegaly with dilatation mainly of the left ventricle (LV) and pulmonary congestion of moderate severity. Electrocardiogram (ECG) showed sinus rhythm, rounded depression of ST segment more prominent in V1-V3, $T$ wave inversion, promiment $U$ wave with pseudo-lengthening $(0.60 \mathrm{~ms})$ of the QTc. The brain computerized assisted scan revealed no tomodensitometric abnormalities. The electroencephalogram revealed a slow wave $(2.5 \mathrm{~Hz})$ activity with overshadowing sharp waves and spikes on the left hemisphere. Laboratory studies revealed severe hypokalaemia $(1.5 \mathrm{mmol} / 1$ normal-3.6-5) and moderately low levels of calcium, $1.95 \mathrm{mmol} / 1$ (normal 2.1-2.6), magnesium 0.8 $\mathrm{mmol} / 1$ (normal $0.9-1.2)$ and phosphate $(1.5 \mathrm{mg} / \mathrm{dl}$; $0.48 \mathrm{mmol} / 1$ (normal $2.5-4.5 \mathrm{mg} / \mathrm{dl} 0.80-1.45$ $\mathrm{mmol} / \mathrm{l})$. The creatine kinase (CK) activity was 2,660 $\mathrm{mu} / \mathrm{ml}$ (normal <230) with increased MB $(30 \%)$ fraction. Blood gases, $\mathrm{pH}$, hepato-renal function and blood count were normal.

Infusional therapy was begun immediately with 
potassium chloride ( $40 \mathrm{mmol}$ every $8 \mathrm{hr}$ ) in a glucoseinsulin solution $(500 \mathrm{ml} 10 \%$ glucose $+12 \mathrm{u}$ of regular insulin/every $8 \mathrm{hr}$ ), magnesium sulphate $10 \%$ (4 vials $10 \mathrm{ml}$ in $0.9 \mathrm{~N} \mathrm{NaCl} 500 \mathrm{ml} / 24 \mathrm{hr}$ ), spironolactone $200 \mathrm{mg} /$ daily orally.

We monitored cardiac rhythm and measured electrolyte values, CK and its MB fraction (Fig. 1) every 12-24 hr. Forty-eight hours after commencement of this treatment, the neurological status of the patient was markedly improved. She was conscious and manifested a right hemiparesis with aphasia and a moderate weakness in the limbs on her left side: electromyography of the right quadriceps muscle revealed moderate signs of myopathic damage. The cardiovascular condition also improved with an increase of blood pressure to $100 / 75 \mathrm{mmHg}$, the disappearance of chest rales and of S3. The heart rate stayed at $60-70 / \mathrm{min}$ without arrhythmias. On the ECG recordings the ST-T anomalies were progressively less pronounced, the $U$ wave less prominent, CK activity decreased slowly to $660 \mathrm{mu} / \mathrm{ml}$ (MB $30 \%)$.

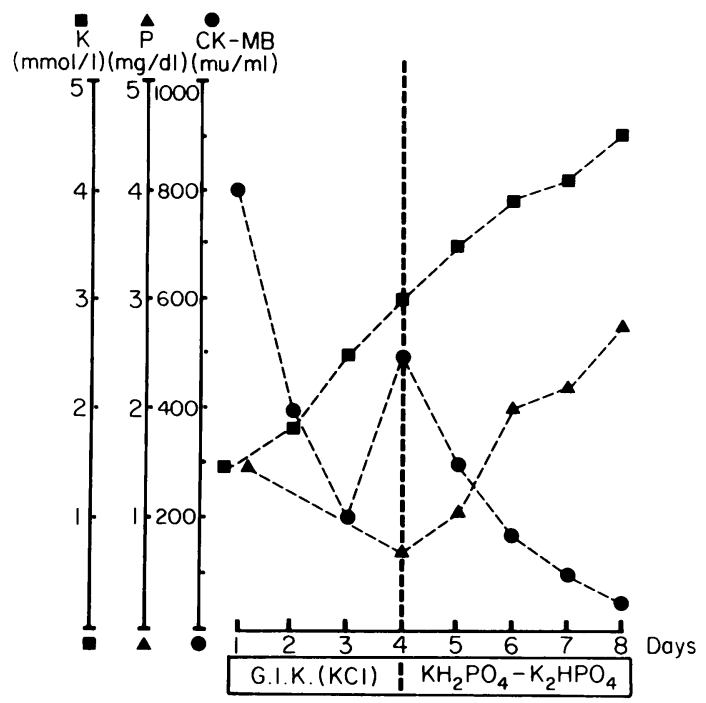

FIG. 1. The trend of biochemical values (potassium: $K \mathbf{E}$ phosphates: $\mathrm{P}_{\mathbf{A}}$; CKMB $\bullet$ ) during glucose, insulin and potassium (GIK), and potassium phosphate infusion.

On the 4th day there was a sudden worsening of the neurological and cardiovascular conditions, the patient became confused, and the blood pressure dropped to $80 / 60 \mathrm{mmHg}$. Rales became audible again in the basal region of lung fields and S3 reappeared. The ECG recording was nearly normal with sinus rhythm $70 / \mathrm{min}$. There was a resurgence of CK to $1250 \mathrm{mu} / \mathrm{ml}$ with MB fraction $40 \%$. A two- dimensional echocardiographic study was carried out with an Irex phased array real time imaging system. $\stackrel{\mathbb{D}}{\mathcal{D}}$ The videotape recording was analyzed in slow. motion, frame-by-frame, by a Cardio 80 micropro- $\vec{F}$ cessor computer, digitizing LV end-diastolic and endsystolic frames to obtain, by a systo-diastolic superposition, the percentual analysis of the LV wall's motion and LV ejection traction (LVEF). The apical four-chamber view showed on the fourth day septal akinesis and lateral wall hypokinesis of LV. The LVEF was $40 \%$ (Fig. 2).

Electrolyte analysis revealed net improvement of serum $\mathrm{K}^{+}(3 \mathrm{mmol} / \mathrm{l})$, but the serum phosphate $\vec{\omega}$ concentration was further lowered to critical levels? $(0 \cdot 8 \mathrm{mg} / \mathrm{dl} ; 0.2 \mathrm{mmol} / \mathrm{l})$ (Fig. 1$) ; \mathrm{Mg}^{2+}$ and $\mathrm{Ca}^{2+}$ wereo in the normal range. Blood cell count revealed a mild anaemia with haemoglobin $11.8 \mathrm{~g} / \mathrm{dl}$.

The infusional therapy was modified, the glucose, insulin and postassium chloride was stopped and a. solution of potassium monohydrogen and dihydro-? gen phosphate salts was made up in $0.9 \mathrm{~N} \mathrm{NaCl}\left(40^{6}\right.$ mmol of $\mathrm{KH}_{2} \mathrm{PO}_{4}-\mathrm{K}_{2} \mathrm{HPO}_{4}$ in $500 \mathrm{ml} 0.9 \mathrm{NaCl}$ /every $8 \mathrm{hr}$ ). Neither digitalis nor other inotropic agents $\vec{\theta}$ were administered. Following the phosphate infusions the serum phosphate, $\mathrm{K}^{+}$and CKMB returned to음 normal; the patient became conscious, the shortness $\stackrel{\Phi}{-}$ of breath, chest rales and S3 disappeared; the BP rose $\vec{\circ}$ to $120 / 70 \mathrm{mmHg}$. After 6 days of potassium ph\$ phate administration a second echocardiographa⿳亠丷厂 study (Fig. 2) was undertaken with the same proce dure: at this examination, on the apical four-chamber view we observed a recovery of the LV wall kinesis, with mild septal hypokinesis and moderate hyperki-응 nesis of the LV lateral wall; the EF had risen to $72 \%$. The patient was discharged 5 days later in good $\overrightarrow{\vec{O}}$ health.

\section{Discussion}

It is known that carbohydrate-rich total parenteral nutrition can induce hypophosphataemia, if there $\frac{\text { 을 }}{3}$ is not an adequate phosphorus intake (Knochel, 1977). In general, significant clinical manifestations are absent because the basal values of serum phosphate are normal, hypophosphataemia is not at a음 critical level $(0.323 \mathrm{mmol} / \mathrm{l})$ or there coexists a metabolic acidosis which, due to the Bohr effect, prevents tissue hypoxia. The phosphate consumption is due to phosphorylation of carbohydrates induced by the insulin that promotes the passage of phospho- $N$ rus and carbohydrates through the cellular mem- $-\mathrm{W}$ branes.

In our patient the cardiac and neuromusculare abnormalities were attributed to hypokalaemia and $\bar{\varnothing}$ there was an initial clinical response to a potassium $\stackrel{?}{+}$ infusion. However she was also deficient in phos- 70 phate $(0.49 \mathrm{mmol} / \mathrm{l})$ as a result of chronic laxative 


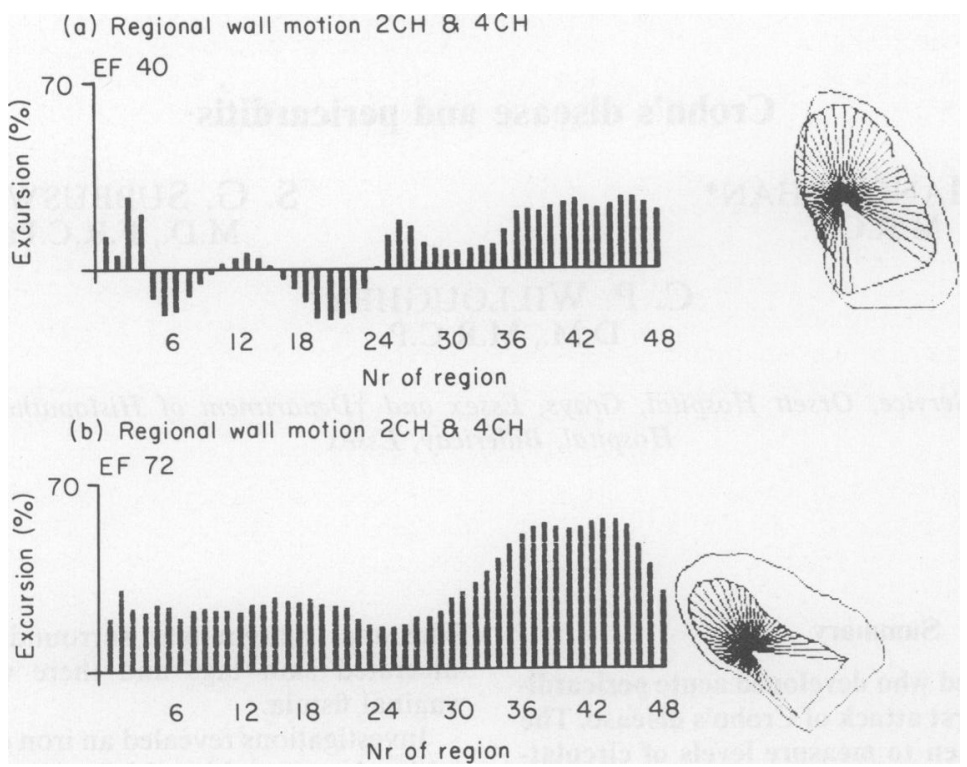

FIG. 2. Segmental analysis of LV kinesis and ejection fraction (EF) by a two-dimensional echocardiographic study in apical four-chamber view, before (a) and after (b) potassium phosphate infusion.

and diuretic abuse. Correction of the hypokalaemia by glucose, insulin and potassium resulted in further depletion of available phosphate to $0.26 \mathrm{mmol} / 1$ with deterioration in her clinical condition and elevation of CKMB. The echocardiographic recording then undertaken (Fig. 2) revealed a marked decrease of myocardial contractility with LVEF of $40 \%$. The administration of potassium phosphate in place of glucose-insulin-potassium produced a normalization of enzyme values and a large improvement in myocardial contractility with LVEF of $72 \%$ (Fig. 2). The second peak in CKMB cannot be attributed to hypokalaemia which was undoubtedly responsible for the first peak, as it was only moderate $(3 \mathrm{mmol} / \mathrm{l})$ at the time.

We would like to suggest that the profound hypophosphataemia induced this second peak indicating myocardial damage and the second episode of functional impairment. These latter changes resolved with phosphate replacement.

Others have described reduction of myocardial performance (O'Connor et al., 1977) as a result of hypophosphataemia. Myocardial damage with elevation of CKMB has not previously been described. In this case the temporal relationship between the plasma phosphate and CKMB changes would suggest such an effect.

At the moment we know little about the pathogenetic mechanism. However a reduced availability of cellular ATP and a reduction of red cell 2,3 diphos- phoglycerate content with impaired release of oxygen from oxyhaemoglobin and tissue hypoxia has been attributed to severe hypophosphataemia (Knochel, 1977; O'Connor et al., 1977).

Therefore we suggest that before use of glucose-insulin-potassium solutions, which as noted (Mantle $e t$ al., 1981) improves left ventricular function in patients with acute myocardial infarction, account must be taken of the basal value of phosphataemia, especially in patients under total parenteral nutrition and patients whose hypokalaemia is the result of drug abuse, in order to avoid cardiovascular side effects.

\section{References}

KNOCHEL, J.P. (1977) The pathophysiology and clinical characteristics of severe hypophosphataemia. Archives of Internal Medicine, 137, 203.

Mantle, J.A., Rogers, W.J., Smith, L.R., MCDaniel, H.G., PAPAPIETRO, S.E., RuSSEL, R.O. \& RACKLEY, C.E. (1981) Clinical effects of glucose-insulin-potassium on left ventricular function in acute myocardial infarction: results from a randomized clinical trial. American Heart Journal, 102, 313.

O'CONNOR L.R., WHEELER W.S. \& BETHUNE, J.E. (1977) Effect of hypophosphatemia on myocardial performance in man. New England Journal of Medicine, $297,901$.

PotTs, J.K., Palakos, T.G., STreeten, D.H.P. \& Jones, D. (1977) Cardiomyopathy in an adult with Bartter's syndrome and hypokalemia. American Journal of Cardiology, 40, 995.

(Accepted 5 October 1983) 